\title{
SLIDING WEAR AND FRICTION BEHAVIOR OF FUEL ROD MATERIAL IN WATER AND DRY STATE
}

\author{
JIN MOO PARK \\ Departmen of Mechanical Design Engineering, Chungnam National University, \\ 220 Gung-dong, Yuseong-gu, Daejeon, 305-764, Korea. \\ sksmswlsan@hanmail.net \\ JAE HOON KIM \\ Departmen of Mechanical Design Engineering, Chungnam National University, \\ 220 Gung-dong, Yuseong-gu, Daejeon, 305-764, Korea. \\ kimjhoon@cnu.ac.kr \\ KYEONG LAK JEON \\ Nuclear Fuel Technology Department, Korea Nuclear Fuel, 1047 Daedukdaero, \\ Yuseong-gu, Daejeon 305-353, Korea.. \\ kljeon@knfc.co.kr \\ JUN KYU PARK \\ Nuclear Fuel Technology Department, Korea Nuclear Fuel, 1047 Daedukdaero, \\ Yuseong-gu, Daejeon 305-353, Korea.. \\ jkpark@knfc.co.kr
}

\begin{abstract}
In water cooled reactors, the friction between spacer grid and fuel rod can lead to severe wear and it is an important topic to study. In the present study, sliding wear behavior of zirconium alloy was investigated in water and dry state using the pin-on-disc sliding wear tester. Sliding wear resistance of zirconium alloy against heat treated inconel alloy was examined at room temperature. The parameters in this study were sliding velocity, axial load and sliding distance. The wear characteristics of zirconium alloy was evaluated by friction coefficient, specific wear rate and wear volume. The micro-mechanisms responsible for wear in zirconium alloy were identified to be micro-cutting, micro-pitting, delamination and micro-cracking of deformed surface zone.
\end{abstract}

Keywords: sliding wear, zirconium alloy, inconel alloy, abrasion, adhesion, nuclear energy.

\section{Introduction}

LWR(Light Water Reactor) fuel rods are composed of a thin tube in which uranium dioxide pellets are stacked. Its slenderness ratio is extremely high since its length is around $4 \mathrm{~m}$ and its diameter is around $1 \mathrm{~cm}$. Therefore, it can vibrate like a string as the coolant passes through the fuel assembly, which is termed as a flow-induced vibration (FIV). This vibration is restrained by its contact with the springs and dimples of a spacer 
grid. The design requirements for the contact force between the supports and fuel rods should be sufficient enough to hold the fuel rods but it should be less than that allowing an axial slip of a fuel rod at the contacts during a thermal and irradiation growth. So, a slipping is inevitable on contacts as long as the fuel rods vibrate. This implies that a fuel fretting wear cannot be eliminated completely. From further research, most of all tests have been performed with zirconium against zirconium alloy which was mid-section of fuel assembly. Because the place that most severe wear occurred was mid-section of fuel assembly. In this study, the combination of contact materials chosen as upper section of fuel assembly. The zirconium alloy against heat treated inconel alloy were investigated as to their abrasive wear behavior under various working conditions by the Pin-On-Disk wear test. Because it is known that fretting wear initiated by adhesion, and when the particles(debris) are subsequently oxidized, abrasion becomes the primary mechanism.

\section{Experimental procedure}

In the Pin-On-Disk test, a stationary pin is loaded axially in contact with a rotating disc, as in the schematic sketch shown in Fig. 1. The sliding distance that applies for this parameter was selected as 10,000 cycles in sliding speed variation and 30,000 cycles in axial load variation and 10,000 to 100,000 cycles in distance variation test. The disc rotates at a speed of 50 to $550 \mathrm{rpm}$ corresponding to a sliding speed of 0.1047 to 1.1517 $\mathrm{m} / \mathrm{s}$ in sliding speed variation test. Also, $500 \mathrm{rpm}$ of sliding speed was applied for another two parameters. In variation of axial load test, The axial load was chosen as 5 to $15 \mathrm{~N}$ that applied for real situation of contact force between rod and grid-spring in a activated reactor and $9.8 \mathrm{~N}$ of axial load was applied for another two parameters. The disk specimen was prepared using a Zirconium alloy which applied for fuel rod material with the dimensions of $56 \mathrm{~mm}$ in diameter, and $0.65 \mathrm{~mm}$ in thickness. The pin specimen was prepared with the dimensions of $83 \mathrm{~mm}$ in length, $6 \mathrm{~mm}$ in diameter. The pin made with Inconel alloy that applied for upper grid material in fuel assembly and to realize the same hardness value the pin was heat treated. The schematic views of the disk and pin specimen and jig are illustrated in Fig. 1. The hardness value of the pin and disk specimens are summarized in Table 1 . The result of abrasive wear evaluated by specific wear rate, $\dot{\omega}$, is defined as

$$
\dot{\omega}=\frac{\Delta m}{\Delta t} \frac{1}{v \rho F_{N}}
$$

Where $\Delta \mathrm{m}$ is the volume loss by wear, $F_{N}$ is the normal load applied on the wear surface and $\Delta \mathrm{t}$ is entire of the test time, $v$ is the rotating speed of disc, $\rho$ is density of the specimen. The meaning of specific wear rate is the rate of material removal or dimensional change due to wear, per unit of kinetic energy[1,2].

$$
\mu=\frac{F_{f}}{F_{N}}
$$



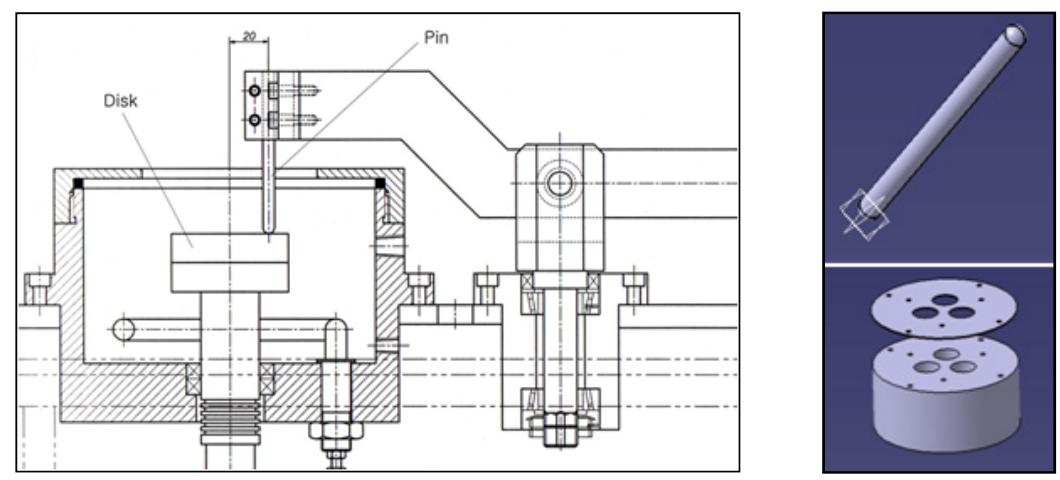

Fig. 1. Schematic diagram of pin-on-disc apparatus and specimens.

Table 1. Vickers hardnesses of pin and disc specimen

\begin{tabular}{|c|c|c|}
\hline \multicolumn{3}{|c|}{ Vickers Hardnesses(HV) } \\
\hline \multicolumn{2}{|c|}{ Pin specimen } & Disc specimen \\
\hline Inconel & Heat treated Inconel & Zirconium \\
\hline $260 \sim *$ & $*^{*} \sim 400 \sim^{*}$ & $290 \sim *$ \\
\hline
\end{tabular}

Friction coefficient describes the ratio of the force of friction between two bodies and the force pressing them together[5]. The friction force between surface and pin specimen was measured by torque-loadcell during the test. In dry friction, the Amonton-Coulomb's law was applied and the friction coefficient calculated like Eq. (2). Eq. (3) is equation for conversion of mass loss to volume loss.

$$
\text { volume loss, } \mathrm{mm}^{3}=\frac{\text { mass loss, } g}{\text { density, } \mathrm{g} / \mathrm{cm}^{3}} \times 1000
$$

\section{Results and discussion}

Fig. 2 shows the data plots of sliding speed variation test. Sliding speed were increased $50 \mathrm{rpm}$ to $550 \mathrm{rpm}$ and dry state tests were compared with in water condition. The specific wear rate and volume loss shows same behavior. They shows biggest values at $50 \mathrm{rpm}$ because of the wear debris which generated by abrasion easily expulsed from contact surface. The volume loss was smallest at the $300 \mathrm{rpm}$. This phenomenon can explained by the change of wear mechanism which shown in Table 2. At the SEM photograph, there was micro-pitting mechanism observed on the worn surface of disc specimen which tested with $300 \mathrm{rpm}$. These micro-pitting mechanism can keep the wear debris and finally the volume loss was smaller than other test conditions. But, the friction coefficient was bigger than other conditions by irregularity of contact surface. The microcutting mechanism was observed at $50 \mathrm{rpm}$ and $300 \mathrm{rpm}$. But at $550 \mathrm{rpm}$ in very high speed, the micro-cutting mechanisms were disappeared and the plastic deformation was only observed because of the shear force can not be delivered to worn surface from stationary pin. Fig. 3 shows the data plots of axial load variation test. Axial load were 
increased 5 to $15 \mathrm{~N}$ and dry state tests were compared with in water condition. This parameter has been chosen for identifying the behavior of wear mechanism by increasement of surface fatigue. The volume loss was increased linearly with increase of axial load. But specific wear rate was decreased and stabilized after $10 \mathrm{~N}$ because of the wear debris which generated by abrasion easily expulsed from contact surface at low axial load. The friction coefficient decreased from low axial load to high axial load. From Table 2, the delamination were observed on the worn surface of disc specimen which tested under $15 \mathrm{~N}$ axial load. In this worn surface, there was no pitting mechanism and only observed delamination and some of micro-cutting existed. Fig. 4 shows the data plots of sliding distance variation test. Sliding distance were increased 10,000 to 100,000 cycles and dry state tests were compared with in water condition. The specific wear rate of two environments shows different behavior. But, both of them were saturated after 50,000 cycles and deformation rate was decreased. Also, the behavior of volume loss saturated similar like behavior of specific wear rate. The friction coefficient of dry state was saturated near the 50,000 cycles but water environment shows different behavior. It increased like dry state to 50,000 cycles and decreased greatly to 100,000 cycle. The reason of this phenomenon explained by SEM photographs as shown in Table 4. In 100,000 cycles, the surface was smoother than the other conditions and micro-cutting mechanism was almost disappeared.

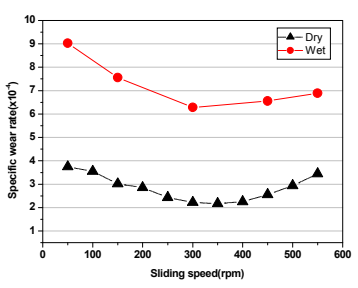

(a)

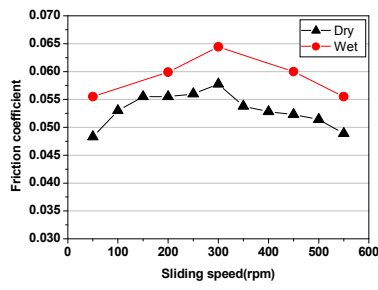

(b)

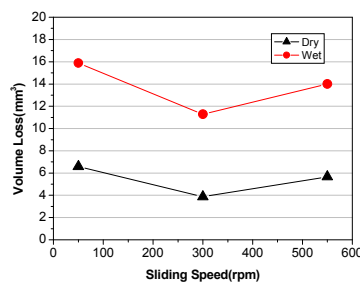

(c)

Fig. 2. Test results as function of sliding speed

( a: specific wear rate; $b$ : friction coefficient; $c$ : volume loss )

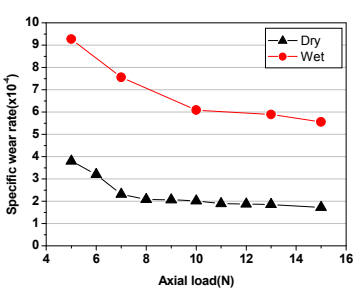

(a)

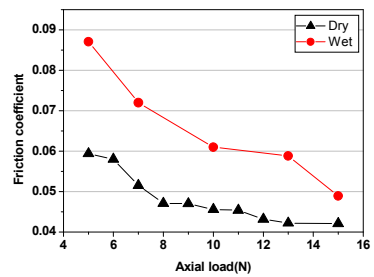

(b)

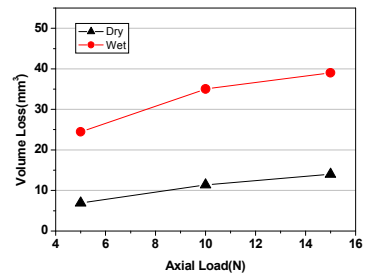

(c)

Fig. 3. Test results as function of axial load ( a: specific wear rate; b : friction coefficient; c : volume loss ) 


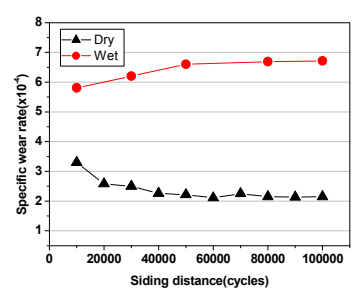

(a)

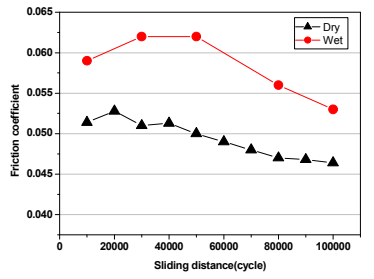

(b)

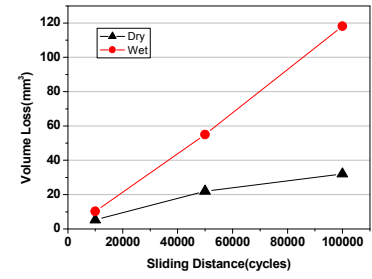

(c)

Fig. 4. Test results as function of sliding distance ( a: specific wear rate; $\mathrm{b}$ : friction coefficient; $\mathrm{c}$ : volume loss )

Table 2. SEM photographs of worn surfaces of the Zirconium alloys tested under three parameters

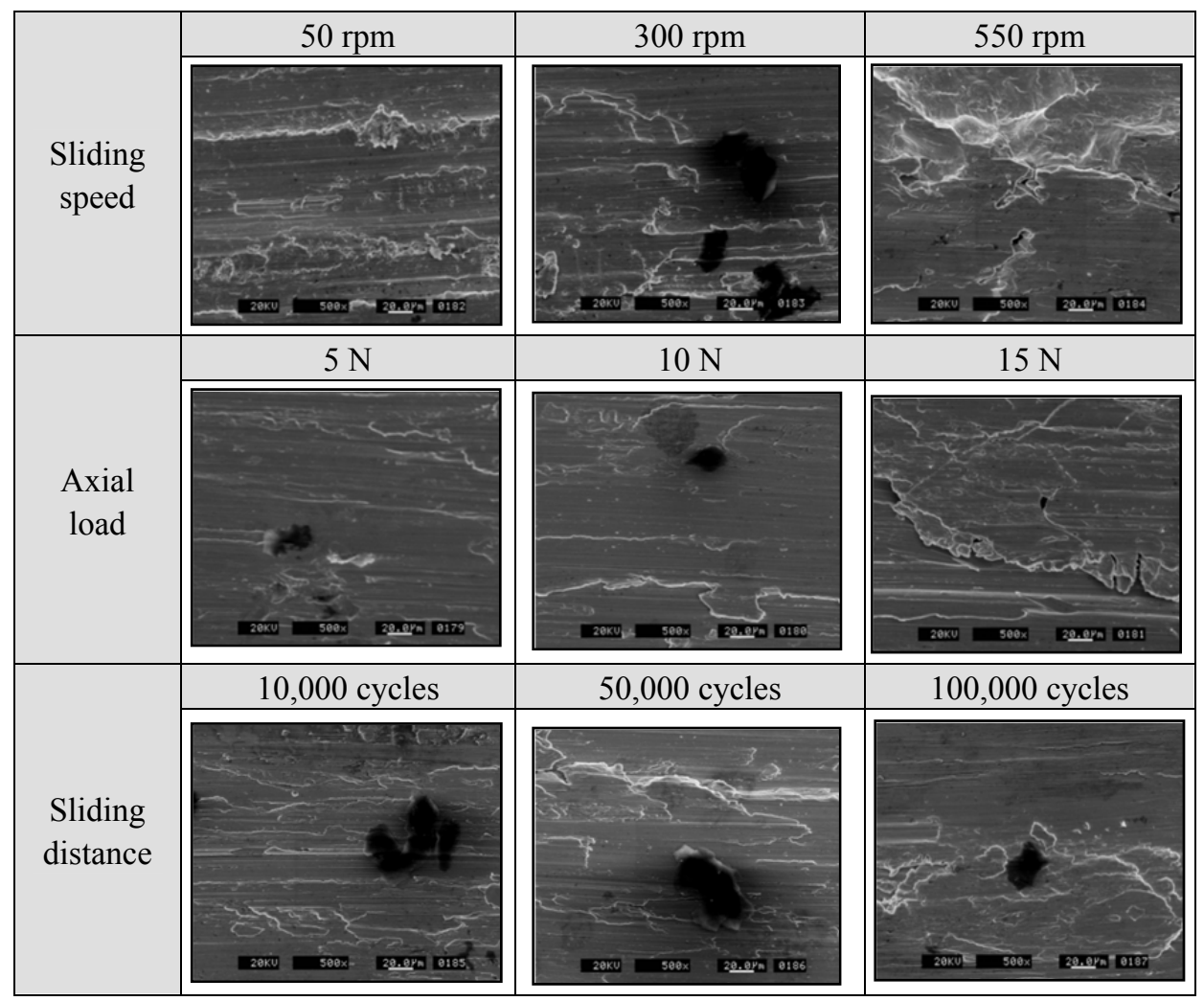

If the wear particle accumulation in the clearance region causes the third body abrasion, it may be supposed that the abrasion is less under the water environment since it is thought that the particles would not be accumulated so that they can be easily removed due to water. However, in comparison with dry and water state, volume loss, specific wear rate and friction coefficient of under water state were bigger than dry state. This implies that 
the wear particles can be accumulated in the clearance region and stay also under the water for some period, and can cause the third body abrasion even in the condition of easy particle dispersion by the water. It also means that the water environment did not remove the particles from the clearances as soon as they were generated. So the role of water in the present wear phenomenon is to accelerate the particle dispersion from the contact surface rather than lubricate the surface, which results in a faster repetition of the adhesion to abrasion cycle. It must be one of the reasons that, in general, a severer wear occurs in the water environment. In other words, it also implies that the wear particle bed forms a load bearing layer that can restrain wear. $[3,4]$

\section{Conclusion}

The wear behavior of fuel rod material against upper grid material was experimentally investigated by abrasive wear test. First of all, the wear resistance of fuel rod material was poor in water environment than air, because the repetition of the adhesion to abrasion cycle was accelerated. Three parameters were applied to experiment and show different characteristics in each test. The wear resistance shows good performance at specific point of sliding speed because the changing of wear mechanism. An increase of axial load causes the plastic delamination on the worn surface by accumulation of surface fatigue. The specific wear rate and volume loss were saturated with increase of the sliding distance by decrease of micro-cutting mechanism.

\section{Acknowledgments}

This work has financially supported by the KEPCO Nuclear Fuel through the project on 2010 .

\section{References}

1. S. W. Koh, B. C. Yang, H. J. Kim, J. D. Kim: Study on abrasive wear behavior of carbon fiber composites, The Korean Society for Power System Engineering 10, 46-51(2006),

2. H. J. Kim, J. D. Kim, S. W. Koh, Y. S. Kim: Effect of counterpart roughness on abrasive wear characteristics of side plate of FRP ship, The Korean Society of Oceanography 22, 35-40 (2008)

3. R. B. Waterhouse, M. K. Dutta, P. J. Swallow: Fretting fatigue in corrosive environment. Proceeding of the international conference in mechanical behavior of materials, Kyoto, Japan; 292-98(1971).

4. P. Blanchard, C. Colombie, V. Pellerin, S. Fayeulle, L. Vincent: Material effects in fretting wear: application to iron, titanium, and aluminum alloys. Metall Trans A, 22A, 1535-44(1991).

5. P. Marklund, R. Larsson: Wet clutch characteristics obtained from simplified pin on disc test, Tribology International 41, 824-830(2008) 